\section{Anthony Walker}

is a founding and senior

partner of architects Damond

Lock Grabowski and Partners,

visiting professor for Kingston

University, visiting lecturer for

the Architectural Association,

and founding member and

chairman of the Leisure

Property Forum.

\section{Keywords}

Leisure, lifestyle, regeneration

heritage, holiday, attractions
Professor Anthony Walker

Senior Partner

Damond Lock Grabowski,

12 Sutton Row,

London W1V $6 \mathrm{AB}$

Tel: 02074396701

E-mail:

anthonyw@dlg-architects.co.uk

\section{Leisure, heritage and the city: A potent combination}

\author{
Anthony Walker
}

Received (in revised form): gth January, 2001

\begin{abstract}
Of all the forms of commercial development it is arguable that property devoted to leisure uses has a greater affinity with the historic qualities of the urban environment than any other. This paper will trace the impact that the provision for leisure activities has had on town layouts, leaving some of the most enduring and location specific features of our urban areas. In an era of the 'experience economy' leisure property is in a unique position to capitalise on the unique qualities of the town. In doing so it must respect the heritage it seeks to exploit, creating a sustainable future and not just a synthetic experience.
\end{abstract}

\section{CONTEXT AND INTRODUCTION}

The provision of leisure activities has left a significant mark on the form of our cities, from open spaces to historic bars, coffee houses and other more substantial buildings. This has combined during the second half of the 20th century with a dramatic increase in interest in the historic environment, and the listing and protection of individual buildings and conservation areas as an understanding grew of the importance of the general character of an area and of the different parts of a town. In many cases the broadening of interest in conservation served to increase the number of buildings at risk and the associated problems of finding economically viable activities which would enhance such buildings without destroying the virtues for which they were to be conserved. ${ }^{1}$ As a generalisation the major commercial uses of offices, factories, shopping centres and warehousing were not only functionally at odds with the conservation objectives, but also organisations sought demonstrably new and modern premises to reflect the organisation's efficiency and modernity. Even with the pseudo-vernacular trends of the 1980s the demand was for easy access by private transport, larger supermarkets, convenient car parks and open wide-span spaces for maximum flexibility. Thus a conflict could be observed between a search for a modernist solution and older buildings reflecting a traditional past.

This is not a universal phenomenon, however. Developers of retail schemes in the final quarter of the century started to appreciate the virtues of specialised centres, epitomised in the USA by Quincy Market in Boston and Fulton Market in New York, or closer to home by the Corn Market at Leeds and more recently 
Windsor Royal Station in Windsor. ${ }^{2}$ These, however, were not the mainstream of this form of development, reflected in their subsection classification as speciality shopping. It was only with the collapse of the commercial property market in the late 1980s and early 1990s that the conditions arose in which leisure property could compete economically. It came as a breath of fresh air. Leisure property could not only make use of historic property with less intervention into the existing fabric, but could also take positive advantage of the characteristics of the area or building in establishing the instant sense of place which was, and is still perceived to be, an essential trait of this type of development. Interestingly this has extended the traditional influence of leisure activities as a catalyst in regeneration. Covent Garden is perhaps the classic example of the success of leisure uses, where leisure retailing has led to colonisation of the area by more mainstream retail outlets, to the possible detriment of the unique qualities of the area. Thus the success of the formula has again introduced tensions between the historic character and the viability of an area.

This paper will argue that the impact of leisure use has been underestimated in our understanding of the development of the city; also that it is distinct in its ability to synthesise with and take advantage of the historic nature of the town in mutual support and regeneration. Further, it will be suggested that leisure binds together a wider range of activities which, affected by e-commerce and the erosion of more traditional forms of business, are seeking new formulae to protect their business activity.

\section{LEISURE - AN OVERVIEW OF ITS HISTORY AND INFLUENCE}

Leisure activities have always been at the core of the city's evolution, and they have played a part largely through the pleasures of the social promenade in the formation of the squares, parks and other open spaces which characterise our towns today. One of the first was laid out by Charles II in 1660 under an avenue of trees providing a shady walk for the enjoyment of pall mall, a malletand-ball game imported from Italy. The games were to disappear, but the walk which became known as the Mall was to retain its attraction for the fashionable as a place to stroll until late in the evening on fine days. ${ }^{3}$ The Pantiles in Tunbridge Wells was first laid out in 1638 as a promenade which developed with rooms for dancing and taking tea. Such walks often defined the town or created neighbourhoods within it. The most sought-after housing in Brighton was round the Steine, while the Quarry walks in Shrewsbury helped to define the fashionable part of town.

The 18th century saw the development of commercial pleasure gardens based on a series of promenades, frequently with a main public walkway and more discreet side walks. Bandstands were provided for music, and provision was made for refreshments. In Vauxhall Gardens Pepys reported seeing jugglers, and there were restaurants, fireworks and illuminations, while on the other side of 


\section{Historic leisure buildings}

\section{Changing attitudes}

The role of transport the river the Ranelagh Gardens had an enormous concert hall, the Rotunda, where one could dine while listening to music. Zoological gardens were another form of open space which developed during the 19th century, providing a commercial opportunity to exploit the public desire for entertainment, although they often had an additional cultural or research objective. Leisure as a social space has therefore been a major design influence on the creation of the urban identity, the sense of place.

If leisure made a major contribution to urban form through its influence on open spaces, it had no lesser impact on the buildings of the town. Fairs attracted various forms of entertainment, sometimes displacing some of the trading element. By the 18th century the fair on Angel Hill in Bury St Edmunds had become the chief social event of the year, accompanied by a theatrical season and a series of balls at the Assembly Rooms. The fashion for assemblies dates from the early years of the 18th century, and they were soon to embrace dancing as part of the ritual. Assembly rooms were financed most commonly by a hotel owner as private speculation, although some were provided by corporations to promote the town and often doubled up as court rooms, for example, the ballroom at the Town Hall in Newark.

On a smaller scale, inns and public houses provided hostelry and, with the benefit of galleried yards, a setting for the plays which had been popularised by strolling players with their origins in the mystery plays of the Church. The companies of players wished to free themselves of the innkeepers and gave rise to an early form of out-of-town development epitomised by theatres such as The Theatre in Finsbury Fields, the Rose on Bankside or the Globe in Southwark, which came into being in the middle of the 16 th century. Cafes and coffee houses did not take on separate buildings until the late 18th century, although their impact on society and commerce had been significant, with Lloyds and the Baltic Exchange growing out of their namesake coffee houses in Lombard Street and Threadneedle Street, while the Stock Exchange emerged from Jonathan's in Change Alley.

By the Victorian era public houses and inns had become magnificent edifices within the centre of the town, contributing much to both the cultural diversity and the economy of the area. Their growth heralded a period of turbulence in the development of towns as the inevitable conflicts arising from their rapid expansion were resolved. Even attitudes to leisure time clashed. Should it be a time for rest, ready for the next day's toil, or a means of letting off steam, a time for self-improvement and on Sunday a church service, or an opportunity to let go and have a good time in order to forget the drudgery of the workplace? ${ }^{4}$

Transport had much to do with the success of leisure in towns. Bath relied on the season, when the whole of society arrived to enjoy the waters or the attendant forms of entertainment. The early seaside resorts stimulated in the second half of the 18th century by 
the enthusiasm for sea bathing, often under royal patronage such as Brighton or Bognor Regis, relied initially on steamers as the most efficient form of transport and developed the pier from a functional to a lifestyle leisure format. ${ }^{5}$

In the 19th century the advent of cheap popular transport in the form of railways combined with the advent of bank holidays to stimulate a demand for entertainment for the working family and to reinforce the seaside resort. Blackpool by 1900 had grown in 50 years from a small village to a resort five miles long with a unique range of buildings whose sole purpose was to serve the needs of a holiday population - the Alhambra, the Winter Gardens 1878, the Empress Ballroom and of course the Tower - while along the promenade ran the first electric trams in England, and the promenade was to become a wonder in its own right as the first to be lit by electric light.

While such a dominant exposition of leisure facilities may have been the exception, every town was to see a dramatic increase in buildings devoted to leisure and to specific leisure uses. Music halls, theatres, large and often glitzy public houses, or groups of restaurants such as the Trocadero were integrated with the main business centre. During the 20th century a range of new uses, such as the lido $^{6}$ and cinemas, ${ }^{7}$ arrived in the town, while ramblers' associations and the advent of the car opened up the countryside. An educational theme was to be found in zoological gardens, which provided large-scale leisure attractions often incorporating sensational modern design - the penguin pool at London Zoo and Dudley Zoo in its entirety were unashamedly modern buildings which have now joined our formal heritage through listing. These were the forerunners of the larger forms of development which were to come to prominence after the Second World War.

The second half of the 20th century saw an explosion of leisure activities, and the ability to travel widely not only extended the range of holiday opportunities but also gave a taste of new activities with the potential to attract a much wider clientele. Visitor and tourist attractions gained a market which recognised this international dimension. Theme parks such as Disney World, which opened in 1995, and Parc Asterix both attract a worldwide audience. The Costa Brava may have suffered from a surfeit of tourists, but the ease of foreign travel introduced many to less commercialised parts where the attractions of the local cuisine opened up opportunities for new forms of catering at home. With this international influence the leisure industry moved from the preserve of small individuals to national and often international operators. For example, AMC multiplexes stretch from their home in Kansas via Europe to Tokyo, Healthland expanded from its South African base, while companies such as Whitbread or Scottish and Newcastle have developed from their brewer origins with ranges of restaurants, bars, nightclubs, health clubs and other outlets. With the advent 
Trends for 21st century

\section{Lifestyle impact}

of major corporate operators there arose the opportunity for property developers to achieve developments with sound covenants attractive to the investment market.

As we move into the 21st century, new leisure property development continues to add diversity to the city. There are several distinct strands that can be identified, one of which is the self-contained centre, such as Heron City or Xscape promoted by Capital and Regional. These seek to create and maintain an individual identity and one which will be recognisable in all parts of Europe; others seek identity but on a one-off basis, such as Star City in Birmingham and the Light in Leeds. Others are leaving it to the operators to provide the branding and image, while at the smaller end of the range individual operators and developers are taking advantage of historic city areas to establish leisure quarters, for example, in the Castlefield area of Manchester and in Nottingham. These scenarios affect mainstream commercial leisure; there are yet further developments in sport and community ventures, and as important is the impact of retail development where leisure has become the essential additional ingredient, whether in a bolt-on style or fully integrated, for example, $\mathrm{O} 2$ in the Finchley Road, London.

In summary, the phenomenon of leisure development as a major influence on the built form and structure of cities is not new, albeit often underestimated.

\section{THE CITY: THE NEED FOR A ROLE}

McIntosh has identified the need for towns and cities to find a new future. ${ }^{8}$ He argues that a structural shift has taken place in the economy of towns and their rationale for existence. Focusing on the move during the 1970s and 1980s to out-of-town retailing and business parks, his words have an even greater significance with the rapidity with which e-commerce is beginning to affect all forms of commercial activity. McIntosh notes that catering for a leisured society is becoming big business, and speculates that where people choose to spend their leisure time may be the salvation of the town and city centres of the 21 st century. Further work ${ }^{9}$ indicates that town centres which embrace leisure uses may be more resilient to economic change than those which do not.

Lifestyles are changing. The working week has substantially reduced over the last century, and while the working life has extended overall, life expectancy has doubled, the result being a substantial increase in non-vocational time before, during and after the main working career. Combined with less time spent on parenting and family care, there is a dramatic increase in the time to be spent on leisure, cultural and educational pursuits at all ages, subject increasingly to the potential customers' economic purchasing power. Frequently those with the power to buy the leisure offer will be those with increasingly pressured work lives, the classic money-rich/time-poor conflict. As more intense and remote 


\section{In the town or of the town}

Regeneration working patterns emerge, the trend will be to seek companionship in our formal leisure time, taking pleasure in being where other people are and deriving 'contact' from their presence. As ecommerce and new working practices drive prices down and stimulate home shopping, they release both time and money for leisure pursuits. The ability to make enquiries and bookings will encourage a wide range of leisure activities, from short away-breaks to increased visits to the cinema and theatre.

How does the new leisure market interact with the city? Is it 'of the town' or merely 'in the town'? Commercial leisure developments face a similar challenge to that of retailing. Should they seek to establish themselves as inward-looking developments self-sufficient with their own brand identity as their marketing strategy, or should they make use of the city to establish an identity as a part of the community, where the attraction of the whole creates a greater draw than the sum of the individual parts? Shopping centres have been criticised for their bland appearance, the same national retailers in the same mix from Plymouth to Aberdeen. Many are turning to 'leisure' as a means of alleviating the ennui generated by such uniformity, to give a sense of place and individuality. ${ }^{10}$ What is referred to as leisure or lifestyle retailing is focused on providing this individuality and interest. How ironic, then, if leisure developments adopt the same genre and philosophy and become a replication of the standard product approach. Yet this is apparent with the formatted leisure park being translated into urban settings, where the need to satisfy the demands of the funder may conflict with the individuality which is inherent in the success of the leisure activity.

McIntosh speaks of 'comeback' cities where the urban framework has been turned inside out. The core deserted by residents, retailing and employment has been rediscovered by the leisure industry, taking advantage of its instant character and ambience, and in its wake return the residents. Leisure has provided, and is providing, the economic generator for urban renewal. Baltimore has seen a complete rejuvenation of the city around the old dock areas driven by catering and other leisure uses, while possibly less visible but no less significant changes have taken place in areas like Covent Garden in London or the Albert Docks in Liverpool, where leisure, in particular in the form of catering and tourist/leisure shopping combined with cultural leisure (art galleries, museums, theatres), has enabled obsolete buildings to gain a new lease of life and act as a generator for further regeneration. Other examples include the overtly tourist attraction of Morwellham Quay in Devon, which recreates a dockside village. In these latter examples the historic fabric has played a major part in establishing the attraction of the area and the atmosphere off which the leisure uses can feed. There is an inherent attraction in these views which provide a romanticised version of what it was like, we 'experience' the docks which we would not have been able - and probably would not have wanted - to visit in their heyday. 


\section{LEISURE AND THE CITY'S HERITAGE}

The importance of heritage to today's society is gaining an increasing recognition, Rupert Sheldrake's theories on collective memory stress the importance of our environment in that process, and its effects on our daily actions. ${ }^{11}$ The ease of access to the past through modern technology has served to heighten awareness of our heritage and its relevance to our own time. An increasingly commercial heritage - presented in the form of 'genuine' historic pub interiors or the quasi-educational museum - is more concerned with image and appearance than authenticity: "there is now virtually nothing that is not considerably more lively after death than it was before'. ${ }^{12}$ A fictionalised past will often have an appeal for an audience for whom time is at a premium, and who in appreciating a historic environment are less concerned with historical accuracy than a pleasurable experience where the provision of modern plumbing, refuse disposal and access for the disabled are seen as essential to even the most authentic experience. ${ }^{13}$

Case study Castlefield
The Castlefield area of Manchester provides an interesting case study. The area was the birthplace of the city, which spread through the surrounding fields during the 18th century. During the 19th century the area became the centre for the warehouses serving the growing city thanks to the arrival of the Duke of Bridgewater's canal in 1765, which was joined by the Rochdale canal in 1805 . Already established as the storage and transport hub of the city, Castlefield was the natural location for one of the first railways in the world, the Liverpool to Manchester railway built in 1830, with a passenger railway station in Liverpool Road. This was followed by a rapid expansion of railways and viaducts into the area, including the Great Northern Warehouse, a multilevel transport interchange with railways on the first floor, warehousing above, road transport at ground level and below ground a link into the waterways system.

With the decline of the textile industries combined with the growth in road transport, the area was a victim of its own success and by the 1960s formed a wasteland close to the city centre. Although Granada Television had established their headquarters there in the 1950s it was not until the mid-1970s that the area's potential was recognised in the city structure plan; by 1979 it was designated a conservation area. This set the scene with a recognition of the qualities of the area and the provision of some powers to protect these. The Central Manchester Development Corporation (CMDC) established in 1988 recognised the importance of tourism to the area and has promoted revitalisation through a series of environmental improvements. It was the development of a range of cultural and leisure activities which turned the corner, with the transformation of the railway station into the Museum of Science and Industry, Granada's studio tour attraction, the development of the canal waterfront with bars and 


\section{Location redefined}

\section{Blurring of boundaries}

restaurants and, more recently, the arrival of the GMex major exhibition hall and adjoining it the current development of the GNW goods interchange into a multilevel entertainment venue with multiplex cinema, health club, restaurants, leisure shopping and entertainment. This activity has provided the basis for other revitalisation projects, including the Creative Industrial Quarter promoted by the Knott Mill Association. There is still much to do, but a healthy balance of commercial and cultural leisure activities are underpinning the resurgence of the area.

Case studies are available for urban regeneration based on other commercial activities, ${ }^{14}$ but leisure uses are almost unique in their natural synergy with the cultural and historic qualities of the city. Unlike most forms of commercial property, which serve essential needs in providing a place to work, manufacture or make purchases, leisure is a fundamentally discretionary activity. It constantly needs to attract in its own right, and to withstand comparison with a wide variety of alternatives.

For leisure developments to succeed, the ability to be renewed as part of a vibrant city fabric is a key factor to their future viability. Indeed, it may be argued that leisure has become the binding force linking a diversity of other activities. As we develop into what has been dubbed an 'experience economy', 15 pleasure and enjoyment of the work process are key factors in every sector. Location is being redefined in relation to shopping, working or communicating with others. A simple laptop and modem connection through a mobile 'phone can enable these activities to take place anywhere, anytime. However, the experience economy is dependent on a physical location in which to create the experience. Leisure elements included within shopping developments are not bolt-on extras but an integral part of the retail offer as they confront the convenience of e-commerce and seek to counter it with an enhanced 'experience'. The workplace is rapidly developing many of the aspects of home working, with places to relax, have a coffee, chat and exchange ideas, and the concept of what constitutes the place of work is under review.

Thus at many levels leisure and pleasure permeate all our actions, providing the common themes which unite the day, until work and leisure become fused together. Restaurants and bars are busy all day, not just with shoppers and sightseers but with workers for whom they are a convenient and pleasant place to meet and conduct a meeting, a concept not unfamiliar to many property agents, while in the evening they are buzzing with activity the moment people leave the office. Retailers are developing 'try-andbuy' concepts, whether it be on an individual basis like NikeTown or an integrated offer such as Xscape where the retailing and leisure provision is seen as complementary and mutually reinforcing, not merely a means of creating awareness of the other's presence but as an integral part of the same process. 
Historic quarters

The integrated offer

\section{KEY FACTORS IN THE INTEGRATION OF LEISURE AND THE HISTORIC FABRIC: THE RISE OF THE LEISURE QUARTER}

Key factors in the success of new retail and leisure concepts are access and ambience. The need for easy access may be from the home or the workplace, and while in the former case the use of a car is often seen as essential, in the latter close proximity to the workplace or user-friendly public transport will be essential. Ambience can be at odds with access, especially private transport, but the advantages of a leisure quarter are that it establishes a destination, benefits from the inherent links to the town's culture and economic past, and provides an instant atmosphere which does not rely on caricature imagery. Such historic quarters endow their components with a sense of place, and are what Sheldrake refers to in his description of the environment as part of the morphic fields which form our collective subconscious. ${ }^{16}$

Covent Garden epitomises the success of leisure uses in colonising a historic quarter, revitalising the area as it has through the regeneration of a wide and diverse range of buildings until a series of often isolated areas combine into a dynamic whole, attracting many of the more traditional operators who envy the footfall and the relaxed atmosphere which enhance their own offers.

Such developments do not rely on ancient buildings alone modern buildings find their advocates. The qualities of the South Bank in London are being fiercely defended, with an inter-wars building (County Hall) providing the backdrop for a range of leisure uses from hotels to an aquarium, the prized Festival Hall and adjoining concert halls and a gallery. To the east an old power station provides the setting for a major art gallery, there is a new Globe, and further along at Butlers Wharf warehouses establish the backdrop for destination catering. It is notable, however, that the development of new structures such as the London Eye are needed to provide the key regenerative influences in helping ensure the long-term prosperity of an area in transition.

Traditionally the places for entertainment were stand-alone buildings close to their customer base: the local public house, the assembly rooms serving a town, or from the 20th century the cinema for the immediate neighbourhood. Some of the centres examined above developed a more integrated set of leisure offers, such as London's Trocadero or the Blackpool Tower, but these were the exceptions, and it was not until the relatively recent past, with the advent of theme parks offering a diversity of distractions and the rise of the speculative commercial development, that there has been a focus on providing a united single building or area of diverse types of leisure.

Out of this initial 'black box' approach to the provision of leisure, where a simple shed was seen as the means of providing flexible accommodation for a range of leisure activities, has grown the urban entertainment centre (UEC), a mix of entertainment operators, usually but not always including a multiplex, within a 


\section{Integrating historic fabric}

single development. Some are developed, sold on and the tenants left to survive or fail by their own devices. Others enjoy varying degrees of management, with branded centres like Heron City and Xscape epitomising the ultimate in 'hands-on' involvement by the developer.

While health clubs look to a ten-minute catchment area and a multiplex operator will look for the population in a 20 - to 30 minute drive time, Xscape with its snow slope looks at a two-hour journey limit and theme parks look beyond national boundaries to attract customers. Clearly with such a disparity in the anticipated catchment area the degree of interdependence with the local community will differ. Early UECs took a stand-alone approach, using the familiar and tried shopping-centre formula of an anchor tenant creating the draw and channelling the maximum number of those customers across the front of the other smaller units. The anchor, usually but not always a multiplex, would be sited to achieve this and any leakage was to be deplored, so integration with the implication of a two-way trade, especially when customers going to adjoining areas might take advantage of precious parking spaces - was not to be encouraged. By contrast, leisure quarters encouraged by local authorities as part of a regeneration programme have not surprisingly made use of individual buildings within a locality integrated with the surroundings, since the objective is to share the economic influence as widely as possible.

The more recent commercial developments have seen a similar move integrating new development with existing structures and in some cases looking outward to the surrounding areas. Broadway Plaza in Birmingham, while being a stand-alone concept, is based on creating a central plaza which integrates with the anticipated pedestrian and cyclist flows in the neighbourhood; Great Northern Experience in Manchester makes use of the listed goods interchange building, and while it provides a central internal focus does also seek to integrate the adjoining buildings in Deansgate.

The Light in Leeds goes further in such an integration, utilising several listed buildings which provide a Radisson hotel, restaurants and shops in an L-shape which restates an existing roadway as a glazed arcade, echoing other similar developments in the city. Nestling in the angle of these streets lies the new building, taking advantage of the natural ground configuration which gives two natural access levels while allowing the lower-level shops to look outwards on to the Headrow. A multilevel development, the Light has exploited the integration of new with the old in creating an atmosphere in sympathy with the city while providing the modern facilities needed for efficient operation. The next generation of Heron City concepts will need to address the issue of whether or not to integrate with the city, to be in the city or of the city, to take advantage of its natural features and networks or to stand out as an independent destination. 


\section{CONCLUSION}

Leisure has had a significant effect on the form of our cities, often leaving a more beneficent influence in the form of parks and promenades and grand buildings for theatres and assembly rooms than many other activities such as mills, warehouses and workers' housing. What the 20th century witnessed was almost a reversal of the historic pattern, encouraging regeneration through the planning system while economic imperatives marginalised leisure in the city centre.

\section{The experience economy}

Now, at the start of the 21st century, in an experience economy leisure makes use of the sense of 'place' provided by the historic city and in turn provides the experience which its customers seek. In doing so it frequently makes use of buildings from other eras and other uses whose economic viability has declined to a point where the combination of aesthetic and cultural value, protection by legislation from demolition and a desperate need for a sustainable use have led to leisure becoming a significant force in the regeneration of run-down areas.

Leisure formed the historic city and is now in a position to take advantage of its heritage. To do so successfully, however, it requires a blend of reuse with new concepts to refresh and add a new dimension to the city experience. What is certain is that bland, standard 'roll-out' formulae developments will not add positively to the social and cultural grain of the city, and as such their long-term sustainability is questionable.

\footnotetext{
References

1. Davies, P. and Keate, D. (1995) In the Public Interest, English Heritage, p. 10.

2. Speciality Centres (1980) Jones Lang Wotton and Design International.

3. Girouard, M. (1985) Cities and People, Yale University Press, pp. 174-175.

4. Girouard, M. (1990) The English Town, Yale University Press, p. 294.

5. Ibid., p. 290.

6. Forsyth, A. (1982) Buildings for the Age, Royal Commission on Historical Monuments, p. 6.

7. Sharp, D. (1969) The Picture Palace, Hugh Evelyn, p. 50.

8. McIntosh, A. (1997) Towns \& Cities, E\&FN Spon, p. 79.

9. Mackintosh, A. and Sayce, S. (1998).

10. Court, Y. (1999) 'Sales performance', Shopping Centre Progress 1999-2000, Estates Gazette, pp. 23-26.

11. Sheldrake, R. (1989) The Presence of the Past, Fontana, p. 198.

12. Lowenthal, D. (1985) The Past is a Foreign Country, Cambridge University Press, p. xv.

13. Urry, J. (1990) The Tourist Gorge: Leisure and Travel in Contemporary Society, London.

14. Tiesdell, S., Oc, T. and Heath, T. (1996) Revitalising Historic Quarters, Architectural Press, Chapter 1.

15. Pine, B. J. and Gilmore, J. H. (1999) The Experience Economy, Harvard Business School.

16. Sheldrake, ref. 11 above.
} 